\title{
Etnografía de un proceso judicial contravencional en la Ciudad Autónoma de Buenos Aires: La loca, la mala
}

Ethnography of a contraventional judicial process in the Ciudad Autónoma de Buenos Aires: the crazy one, the bad one

Valeria Herrera ${ }^{1}$

\section{Resumen}

La Declaración Universal de los Derechos Humanos, a la cual Argentina adscribe, establece una serie garantías que los países firmantes deben garantizar a su población. En relación al sistema jurídico, los más relevantes vinculados con el propósito de este trabajo son: "todos son iguales ante la ley", "toda persona tiene derecho a un recurso efectivo ante los tribunales nacionales competentes", "toda persona tiene derecho, en condiciones de plena igualdad, a ser oída públicamente y con justicia por un tribunal independiente e imparcial", "toda persona acusada de delito tiene derecho a que se presuma su inocencia mientras no se pruebe su culpabilidad”. Respecto a este último tanto, la Constitución Nacional, en su artículo 18, como el Código Penal Procesal de la Ciudad Autónoma de Buenos Aires en su artículo 7, determinan lo mismo. En este trabajo me propongo describir y analizar la vulneración de los derechos antes descriptos en un proceso judicial, por una contravención según el código Contravencional de la Ciudad Autónoma de Buenos Aires.

A través de una etnografía de dicho proceso, intento describir y reflexionar sobre la violencia institucional que padecen las personas que transitan los mismos, cristalizada en el marco que la normatiza, permite y reproduce, dando cuenta del rol punitivo y represivo del mismo y violando los derechos que la Constitución Nacional establece, y que la Declaración de los Derechos Humanos garantiza.

Palabras claves: Violencia institucional, mujeres, contravenciones, derechos humanos, etnografía

\section{Abstract}

The Universal Declaration of Human Rights, to which Argentina subscribes, establishes a series of guarantees that signatory countries must guarantee to their population. Regarding the legal system, the most relevant guarantees related to the

Recibido: 1 de octubre de 2021 Aceptado: 20 de diciembre de 2021 Publicado: 7 de enero de 2022

${ }^{1}$ Profesora de Ciencias Antropológicas y Tesista de la Facultad de Filosofía y Letras, UBA. CABA, Argentina. Correo electrónico: val.herreracastonjauregui@gmail.com 
purpose of this work are: "everyone is equal under the law", "every person has the right to an effective recourse in front of the competent nacional courts", "every person has the right, in conditions of full equality, to be publicly and fairly heard by an independent and impartial court", 2every person accused of a crime has the right to presumption of innocence until proven guilty". Regarding the latter, both the National Constitution, in its article 18, and the Criminal Procedure Code of the Autonomous City of Buenos Aires, in its article 7, determine the same thing. In this work I propose to describe and analyze the injuring of the rights described above in a judicial process, due to a transgression according to the Contraventional Code of the Autonomous City of Buenos Aires.

Through an ethnography of this process, I try to describe and reflect on the institutional violence suffered by people who pass through them, crystallized in the framework that regulates, allows and reproduces it, reporting their punitive and repressive role, violating the rights that the National Constitution establishes and that the Declaration of Human Rights guarantees.

Keywords: Institutional violence, women, contraventions, human rights, ethnography

\section{Introducción}

Desde hace años, organismos de derechos humanos primero, y luego el Estado argentino, hacen uso de la categoría "violencia institucional" no solo para referirse a actos llevados a cabo por las fuerzas de seguridad en su conjunto, sino como una categoría local, cuyos alcances trascienden dicho conjunto. Es así que, desde el Equipo de Antropología Jurídica de la Facultad de Filosofía y Letras de la Universidad de Buenos Aires, se han realizado diversas publicaciones para dar cuenta del proceso de ampliación de la misma. Tal como sostiene Victoria Pita (2016), en la actualidad hablamos de una categoría política local, situada; lo cual significa que refiere a la experiencia tanto próxima como distante -parafraseando a Geertz. Próxima dado que se vincula a lo vivido por el nativo, en este caso, las víctimas directas de violencia policial, de Estado, del sistema jurídico. Distante, refiriendo al quehacer científico, analítico. De este modo, ambas experiencias unidas, dan origen a la categoría analizada. "Se trata de una noción con un significado relativamente extendido que consigue identificar, clasificar y también calificar un tipo de prácticas y de hechos, unas formas de hacer, unos estilos institucionales y unos actores en el campo de lo que puede ser presentado como violencias de estado" (Pita, 2016). Continuando con el trabajo de esta autora, podemos identificar cuatro tipos de violencia institucional, 
los cuales se vinculan con diferentes patrones culturales. En primer lugar, se encuentran las prácticas más graves, que refieren al quehacer cotidiano de las fuerzas de seguridad, a los cuales Tiscornia (1998a) denomina hechos "extraordinarios". En un segundo grupo, encuadran todas las prácticas cotidianas vinculadas al "olfato policial”. En tercer lugar, en donde este trabajo hace hincapié, encontramos al poder judicial, cuyo accionar garantiza y reproduce la violencia institucional. Por último, tanto estas prácticas como algunos aspectos del proceso jurídico autorizan nuevas practicas que revisten el carácter de violencia institucional, como es el caso de la incriminación por sospecha.

\section{Laberinto judicial: presos antes de la prisión}

El día 3 de agosto de 2021, una Fiscalía Penal y Contravencional de Faltas, una Defensoría y un abogado particular reciben el mail que en párrafos posteriores transcribo. El mismo forma parte de la "zona opaca" (Tiscornia, 2008) de la perversión del sistema jurídico, cuyos ejemplos se repiten si de violencia hacia mujeres se trata. Basta ver las estadísticas del Observatorio “Ahora que si nos ven”, el cual informa que durante el 20202 de cada 10 víctimas habían realizado una denuncia, y solo 19 de las 298 tenían medidas de protección, siendo de todas maneras asesinadas. El informe es contundente "esto se da en un contexto en que el 13\% de las víctimas estuvieron desaparecidas previamente, y como sucedió en distintos casos, no se le tomó la denuncia a la familia e incluso se las culpó. El mismo observatorio, informa la situación de víctimas de violencia de género para la primera mitad del año 2021 donde se registraron 176 femicidios, de las cuales 28 víctimas habían realizado al menos una denuncia, y solo 16 tenían medidas de protección.

El padecimiento de aquellas personas que están transitando procesos judiciales en la Ciudad de Buenos Aires, pone a víctimas y denunciados ${ }^{2}$ en estados de total indefensión, ciegos y sordos ante la situación que los atraviesa, cosificándolos como un expediente más (tipificado de acuerdo al artículo que corresponda) que deben cerrar para alcanzar el objetivo del mes y aumentar sus estadísticas de casos resueltos. por otro lado, cabe resaltar que los abogados y el Colegio de Abogados conforman una corporación.

Me motiva la imperiosa necesidad de concluir con este proceso que tiene entre paréntesis mi vida desde que comenzó, por el cual fui injuriada, amenazada, hostigada, me enfermé y tuve problemas con mis estudios,

\footnotetext{
${ }^{2}$ En este caso, hablo de víctimas y denunciados (omitiendo la palabra victimario), debido a que es la misma persona la que se encuentra de ambos lados, siendo esta víctima de acoso y hostigamiento, el cual incluye falsas denuncias que la pusieron en lugar de denunciada.
} 
entre otras cosas; pero sobre todo es el DESAMPARO, DESPROTECCIÓN, FALTA DE RESPUESTAS Y DECEPCIÓN.

Entiendo que, si llegué a esta instancia, es porque desde el momento que quien inició la querella presentó pruebas, me consideraron culpable, o dieron lugar a la duda (perdón si no me expreso de la forma técnicamente correcta, hablo desde el sentido común). Sin embargo, sostengo MI INOCENCIA, y que actué de buena fe, de hecho, esto debería estar explicado en el escrito que debería haber presentado mi primera letrada (hablo en potencial, dado que desde que contraté al Sr XXXX, a quien le pagué U\$D 1000 para que ME DEFIENDA, no pude ver nada de mi causa); quien renunció a mi patrocinio dado que me hacía preparar los escritos a mí, no respondía mis consultas (similar a la situación actual, aunque no tan grave), no presentaba la documentación en tiempo y forma. ¿Por qué digo que esta situación que estoy viviendo con este letrado es más grave que la anterior? Porque ME SIENTO PRESA DEL SISTEMA JUDICIAL. CIEGA ANTE LOS HECHOS QUE ME ENDILGAN. ATADA DE MANOS PARA DEFENDERME y SIN VOZ. Porque quien contrate para que ME REPRESENTE Y DEFIENDA, PROMETIÓ HACERLO, prometió denunciar a la letrada anterior, prometió ejecutar la ACCIÓN PRECAUTORIA DE DAÑOS que tengo a mi favor contra uno de los testigos de la causa que tramita en vuestra fiscalía, PROMETIÓ PROTEGERME. Y mientras me amenazaban de muerte y hostigaban por redes, me siguieron haciendo falsas denuncias (menos fundamentadas que esta), el doctor xxxx solo me decía que me quedara tranquila.

ME MANIPULÓ PARA ACEPTAR UN ACUERDO, SI. ME MANIPULÓ, PORQUE YO QUERÍA DEFENDERME. Porque estas acusaciones son falsas, porque jamás amenacé, porque nunca fui a un domicilio, porque nadie perdió el trabajo por mi responsabilidad. Porque la denuncia inicia con una mentira: LA QUERELLANTE DICE NO CONOCERME, Y TENEMOS UNA FOTO JUNTAS (la cual la letrada anterior debería haber adjuntado en el escrito que, a esta altura, no se si se presentó).

¿CÓMO ACEPTAR UN “ACUERDO”, SI SE PERFECTAMENTE LO QUE HICE Y LO QUE NO? SI HAY PRUEBAS... ¿POR QUE NO DEFENERME? El doctor me dijo que la causa estaba complicada, porque la agarró "con el partido empezado", y que las personas que me querellaron tenían maldad, y que hasta habían PEDIDO MI DETENCIÓN, y que, dado que estoy por recibirme (...) , ME CONVENIA ACEPTAR EL 
ACUERDO Y DAR VUELTA LA PÁGINA, Y NO EXPONERME A UN JUCIO. ¿EXPONERME? Si ya me expusieron. Me trataron de loca, los seguidores de la querellante me escribían cosas terribles (también deberían estar adjuntas en la causa), la testigo publicó cosas de mi intimidad, (insistiendo con las enfermedades mentales), me acusaron de SECUESTRAR A UN GATO, de ser peligrosa. TODAS MENTIRAS. PERO, LO MEJOR ERA ACEPTAR LA CULPA.

Por supuesto, que si TU LETRADO, te dice que es lo que te conviene, le crees.

Cuando me notificaron que la causa se elevaba a Juicio, me lo notificaron a mí, y no a mi letrada, COLALPSE Y BUSQUE AL DOCTOR xxxx, quien, como manifesté, prometió defenderme, y cuidarme, pero no lo hizo. SOLO SE APROVECHÓ DE MI NECESIDAD Y MI VULNERABILIDAD.

Estos hechos, absolutamente todos, fueron relatados y acompañados con la documentación necesaria el día que contrate al Dr. xxxx, el 16 de marzo 2021.

Pese a mi descontento con el accionar del letrado, firme la propuesta de acuerdo que se supone presentó el día previo a que inicie la feria.

Lamentablemente, esto no concluyo aquí. El lunes 19 de Julio, me llega una notificación: MPFXXXX / xxxxx (la cual cursa en fiscalía penal y contravencional $\mathrm{x}$ )-por lo que leí, se trata de desobediencia a la autoridadLlamé a mi letrado, y al no responder, le mando foto de la misma. Me solicitó que no responda, que por la tarde me llamaba. No lo hizo. El 20 de Julio, envío mail a dicha fiscalía, informando que el Dr. XXXX era mi letrado, poniéndolo en copia, y dejando su número de teléfono. Por la tarde, el doctor me llamó manifestando que el estaba de vacaciones y que no me podía representar. Me pidió que volviera a mandar un mail, diciendo que elegía la representación oficial, y que él -al regresar de sus vacaciones-, tomaría la causa, dado que, sino estaba muy jugado con los tiempos, ante lo cual respondí que me parecía una desprolijidad, una falta de respeto y una estafa. Que ambas denuncias están relacionadas, y que él me había manifestado que los U\$D 1000 eran por toda la causa XXXX, e incluso por la causa de la testigo (la vecina que me amenaza y hostiga). El día que aboné, le llevé una carpeta gigante con todo lo que había pasado, incluso la "notificación" que no era tal, los mails de la abogada. Es más, hace unos meses, me llegaron notificaciones a mi Gmail de que estaba 
haciendo publicaciones que infringían las normas de Google. Se lo informé y no hizo nada.

La testigo me envió cartas documentos, manifestando que yo estaba deambulando por su domicilio, que había entrado a robar, que molestaba a la encargada de su edificio, etc. También dicha testigo XXXX, envió una carta documento a mi madre, adjudicándole responsabilidad en caso de que a ella le pasara algo por un accionar mío, dado que, según manifiesta xxxx en todas sus agresiones a mi persona, yo no estoy bien "mentalmente" (hostigamiento que sostiene desde el 22 de junio del 2020 y que deja en evidencia el rechazo y odio que tiene esta persona hacia las personas que van al psiquiatra o psicólogo, y que tienen algún tipo de trastorno mental dado que también le escribió a mi psiquiatra)

ESTO ME PARECIÓ UN MAMARRACHO. ¿PERO CÓMO PUEDEN PASAR ESTAS COSAS? Quienes atravesamos un proceso judicial, si estamos disconformes con algo, concreto, real, repudiable, turbio, debemos callar o pagar otro letrado. El colegio de abogados no actúa si no sos famoso, y nosotros, los simples mortales, perdemos plata, y pagamos penas que no nos corresponden.

¿CÓMO ANTE TANTAS PRUEBAS, TANTOS HECHOS QUE TIRAN DE RAÍZ LA FALSA DENUNCIA EN LA QUE ESTOY ENVUELTA, EL SR xxxx NO ME PODÍA DEFENDER, ALEGANDO QUE NO ERA CONVENIENTE? ¿Cómo?!!!

Por esto, y muchas cosas más que sería imposible redactar sintéticamente, es que RENUNCIO AL PATROCINIO DEL SR $\mathrm{xxxx}$ Y SOLICITO UN ABOGADO DEFENSOR DE OFICIO.

Por otra parte, MANIFIESTO MI ENTERA DISPOSICIÓN ANTE ESTA FISCALIA PARA xxxx CON ESTA CAUSA, QUE LLEVA TANTO TIEMPO, Y TANTO DAÑO ME HA HECHO POR ÚLTIMO, SOLICITO EL ACCESO A MI CAUSA, DADO QUE MI LETRADO JAMÁS ME LA FACILITÓ PESE A HABERLO REQUERIDO EN REITERADAS OPORTUNIDADES. ${ }^{3}$

A través de la reconstrucción de esta telaraña de denuncias intento mostrar como actualmente "la justicia" no busca cumplir la función social que el Estado le otorga, sino despachar casos con la estrategia del juicio abreviado partiendo, como sostiene Eilbaum (2004) de la "incriminación selectiva por sospecha" (de modo tal que

\footnotetext{
${ }^{3}$ Las mayúsculas son del mail transcripto
} 
las estadísticas demuestren la eficiencia de la Fiscalía, el Juzgado y la Defensoría interviniente).

Por otra parte, hipótesis que se desprende de las causas, pruebas, declaraciones, pericias, etc., me propongo describir cómo el Código Contravencional lejos de buscar modificar las conductas y prácticas que atentan contra el orden público, (consideradas antidemocráticas) opera como un aparato de control social, y de represión, estigmatizando a los sectores minoritarios y excluidos como peligrosos; escuchando enfáticamente el pedido del "buen ciudadano".

\section{El caso}

En junio de 2020, inicio de la pandemia, por cuestiones de convivencia vecinal, Ana ${ }^{4}$ comenzó a ser hostigada y amenazada por una vecina. Las acciones llegaron a un nivel tan alto de amedrentamiento, que un juzgado civil dio lugar a una medida cautelar (lo que se conoce como perimetral, pero en este caso, era digital). Pese a que la agresora se mudó en septiembre del mismo año, la actitud amenazante continua hoy en día. Según lo que relata Ana:

El 22 de junio le pedí por WA que bajara la música. Ella se mostraba enojada y me dijo que no, que la denunciara, que yo me la pasaba gritando, entre otras cosas. Al ver que seguía con las agresiones, la bloquee. Y creo que eso fue el detonante de su ira. Me agredió por Facebook, la bloquee. Siguió en Instagram y la bloquee. Como no le quedaban más redes, (o eso creía yo porque una semana después vi que me escribió al que tengo de artista plástica), me mandó más de cincuenta mails con agresiones y amenazas (...) El nivel de agresión y maldad es superlativo, me trata de loca, enferma mental, vividora, me amenaza con encerrarme y sacarme a los gatos, que me va a tirar la puerta abajo. Publicó fotos mías, recetas de mis médicos, le escribió a mi psiquiatra. Está obsesionada conmigo, me denunció por maltrato animal, motivo por el cual me allanaron la casa. La denuncia quedó archivada porque mis animales viven mejor que yo. Ella utilizó eso como una forma de dañarme, porque sabe lo que significan para $\mathrm{mi}$

Pese a que existe una instancia legal civil que "protege" a Ana y a que la comisaría vecinal le entregó por medio de un oficial "medidas de seguridad", la fiscalía consideró que los elementos aportados como prueba, sumados al descargo presentado

\footnotetext{
${ }^{4}$ El nombre es ficticio para resguardar la identidad de quien actualmente, es víctima e "imputada"

${ }^{5}$ La medida de seguridad es una fotocopia con los números de la comisaria y de los patrulleros del barrio.
} 
por la vecina ${ }^{6}$, determinaban que se trataba meramente de un conflicto vecinal y privado, motivo por el cual la fiscal decidió archivar la causa. Ana solicitó la revisión del caso, derecho que le otorga la ley, aportando nuevas pruebas, y solicitando que investiguen. Nunca recibió respuesta. Solicitó asistencia a la víctima, la llamaron y le consultaron si tenía asistencia psicológica privada, y le indicaron que, para sentirse segura, al salir de su departamento, lo hiciera con su celular en la mano, y con el 911 como número a marcar primero. Lo relatado por Ana, fue analizado con mucha claridad por Mariano Sicardi ${ }^{7}$, quien sostiene que la justicia en la Ciudad de Buenos Aires tiende a ser una "justicia managerial", cuyo objetivo ya no es la resolución de un conflicto, sino el cumplimiento eficaz y eficiente de las metas planteadas para el Ministerio Público Fiscal de la Ciudad, las cuales se tomaron de modelos de gerenciamiento empresarial, y que se construyen a partir del establecimiento de objetivos, control de la "producción" (resolución de casos), medición del tiempo, costos y división del trabajo.

Ana se siente desprotegida y asustada y si bien hay un claro conflicto que requiere de la intervención de la justicia, no solo por las amenazas y el hostigamiento, sino por la vulneración a su intimidad, con publicación de fotos, recetas médicas y divulgación de información intima, ya no es de interés para el Ministerio Público Fiscal (en adelante, MPF) encontrar una solución que de tranquilidad a la víctima, sino cerrar el caso, archivándolo o como veremos más adelante, convirtiendo a la víctima en victimaria, y "cerrando el caso" con un juicio abreviado.

Tomo este caso, como caso testigo para mostrar la relación entre violencia institucional y violencia de género, dado que por un lado, vulnera los derechos de Ana al no ser escuchada, al reducir las amenazas y hostigamiento a ámbito de lo privado donde la jueza dijo no poder intervenir, dejando en evidencia la falta de compromiso con la tarea encomendada, el incumplimiento de los deberes de funcionarios públicos, y las acciones y omisiones tendientes a garantizar la

\footnotetext{
${ }^{6}$ La vecina argumentó que Ana también la amenazó y hostigó, pero no presentó pruebas. Solo un mail donde le reclamaba que le pagará $\$ 500$ por unas impresiones. En palabras de la actual abogada de Ana: "es muy común que quien hostiga, utilice falsas denuncias para hacerlo, generando más temor, ejerciendo una violencia psicológica que tiene como herramienta el aparato estatal”, agrego, estatal opresor.

${ }^{7}$ Para conocer sus postulados remitirse a: "El juicio abreviado como mecanismo de gestión de casos. Una mirada a partir de las prácticas del Ministerio Público Fiscal porteño" (2018); "Cuando lo inquisitivo se encuentra con lo adversarial: Apuntes sobre los procesos de reforma judicial y el caso de la Ciudad de Buenos Aires (Argentina)” (2019); “CCuerpo extraño? El proceso de flagrancia en el fuero criminal y correccional ordinario del Poder Judicial de la Nación (2019)”, entre otros.
} 
reproducción de la violencia institucional que al no escuchar a las víctimas es cómplice de la violencia de género. ${ }^{8}$

En septiembre del 2020, con motivo de la finalización de su contrato, esta vecina se mudó, y Ana creyó que todo se iría acomodando, pese a que no hubo intervención de la justicia contravencional. Sin embargo, este estado duró poco, dado que los posteos en redes continuaron, tanto en Facebook como en Twitter. Ahora la exvecina la acusaba de haberse presentado en el actual domicilio, y haberle intentado robar. Ana denunció este hecho, como así también una amenaza de muerte de una amiga de aquella. Paralelamente, y en un acto que podríamos entender en el marco de lo que Marcel Mauss (1979) denominó don y contradón, o su teoría de la reciprocidad; la exvecina hizo una "alianza" con una persona denunciada por Ana por malversación de fondos respecto a donaciones para una escuela en India (a partir de aquí, para referirme a esta persona, hablaré de la fundadora, dado esta ha manifestado en sus redes y medios digitales indios, franceses y argentinos haber fundado dicha escuela). Si bien el trabajo de Marcel Mauss refiere a tribus - basado en los estudios de Malinowski en las Islas Trobiand, Polinesia y otras tribus de Norteamérica-, considero que dicho análisis es aplicable al caso analizado por los motivos que detallo a continuación. En primer lugar, hay un deseo o voluntad de la exvecina de generar una correspondencia entre ambas, donde ella se ofrece a ser testigo, esperando recibir una devolución de este favor. De esta manera, el don entregado "ser testigo", obliga a la contraparte a devolverlo, dado que es la única forma de librarse del contrato establecido. En segundo lugar, la reciprocidad en las tribus estudiadas tiene la función social de garantizar la reproducción social de la misma, la cual puede dividirse en dos: a) el valor de uso del bien dado, por ejemplo, en una vasija de barro, la función inmediata que le reconocemos es cocinar, juntar agua, etc.; b) pero hay una función oculta, el objeto es investido por una función por ambas partes de la sociedad o grupo, la cual podría ser, por ejemplo, garantizar la paz. En el caso de estudio, ser testigo en una denuncia, implica afirmar lo denunciado, o aportar más datos que comprometan a la persona denunciada, y éste es el objetivo que, según el abogado de Ana, tienen ambas personas.

\footnotetext{
${ }^{8}$ Me refiero a violencia de género, dado que, si bien las amenazas son realizadas por una mujer hacia otra mujer, existe una asimetría entendiendo que el machismo es ejercido tanto por hombres como mujeres, y considerando la misoginia internalizada como el factor principal en este caso.
} 


\section{La loca. Justicia ausente, incriminación por sospecha, y estigmatizadora}

Ana recuerda que un día, siendo la una o dos de la mañana, y en cuarentena estricta, la vecina recibió la visita a dos hombres. A los gritos, con el único fin de ser escuchaba relata que la vecina decía

para mi es tortillera, y como un día me recibió en corpiño y boxer y no le di bola, por eso está así. Pero a los 10 minutos, cambiaba el discurso, y decía que yo necesitaba pija, y los tipos respondían que yo era canosa, que no daba, entonces ella les dijo que me pusieran una almohada en la cabeza. ¿Por qué yo tengo que aguantarme eso? ¿Para que está la justicia si no es para cuidarnos de estas amenazas e insinuaciones? Trate de pedir ayuda por todos lados, ONGs, agrupaciones feministas, organismos del estado. ¿Sabés que te dicen? Que no pueden hacer nada, porque no es violencia de género, igual sabemos que, si fuera así, tampoco harían nada, sino, no habría los femicidios que hay. Ellos son tan responsables como la vecina, ellos señalan, discriminan, estigmatizan. Si lees todo lo relacionado con la salud mental que hay en estas denuncias, las barbaridades que la vecina dice, y las cosas que desde la fiscalía preguntan y reproducen, como algo normal, como si estuvieran hablando de mi color de pelo, es tan doloroso, porque no solo no me defendieron sino que, en algún punto, siento que creyeron el cuentito que les contaron. Ellos prefirieron primero, archivar mis denuncias porque se supone que era un problema entre vecinas, y porque soy una enferma psiquiátrica, y luego, avanzar con la denuncia contra mí, sin tener pruebas, porque soy una enferma psiquiátrica

La incriminación selectiva por sospecha, tal como desarrolló Eilbaum, versa sobre esto. Si bien la autora refiere a los casos de procedimientos policiales fraguados $^{9}$, la idea del montaje de un delito, del señalamiento del culpable por sospecha, la famosa "portación de cara" ${ }^{10}$, también opera en el nivel judicial.

En junio de 2020, Ana recibió más de 50 mails de su hostigadora, entre ellos los siguientes mensajes: "vos acordate que estás mal psiquiátricamente", "en cuanto muestre todo lo que tomás cagaste", "te voy a hacer encerrar por loca". Como parte

\footnotetext{
9 (...) "operativos policiales caracterizados por la escenificación de hechos delictivos y la consecuente victimización de personas ajenas al hecho que resultan detenidas, procesadas y encarceladas" (Elibaum,2004: 79)

${ }^{10}$ Los antiguos Edictos Policiales habilitaban a los oficiales a detener "sospechosos" para averiguación de antecedentes. Desde diversos sectores de organizaciones sociales y Derechos Humanos, este proceder fue señalado como discriminatorio y anticonstitucional.
} 
del acoso, publicó recetas de su doctora, diciendo "tengo una vecina que toma todo esto, está re loca”; como tenía esa receta se contactó con la psiquiatra de Ana. En su descargo ante la fiscalía, la exvecina manifestó: "que sabía que Ana padecía un trastorno psiquiátrico que con la cuarentena se acrecentó (...), sostuvo que lamentablemente Ana padece una enfermedad psiquiátrica, y que tiene antecedentes de internación, cometiendo conductas desarregladas de manera sistemática de las que ha sido víctima”. En referencia a la acusación que le hace a Ana de haberle hackeado las cuentas, expresa que se contactó con sus clientes informando que "se trata del ataque de una paciente psiquiátrica”.

El desconcierto de Ana por el proceder de la justicia no deja dudas: "lo peor de todo, es como la justicia da lugar a estos dichos, como se hace eco de tantas barbaridades, no hay nadie capacitado para ver el nivel de obsesión que tiene conmigo y con las enfermedades mentales?, fíjate la denuncia que ella me hizo... los argumentos de aire que da, donde de 10 palabras, 3 o 4 están relacionadas con la locura”.

En su denuncia, la exvecina, retoma estos argumentos como modo de montar el perfil de persona peligrosa, criminalizando a quienes padecen o padecieron algún tipo de enfermedad mental. Su declaración testimonial finaliza "ella es psiquiátrica, tiene trastorno límite de personalidad, se encuentra diagnosticada por la psiquiatra”. (...) "en un corto plazo pude notar que era una persona con una problemática particular, por su alto nivel de conflictividad, y al principio pensé que necesitaba mayor atención, porque pensé que podría existir un problema psicológico o quizás psiquiátrico". En uno de los informes del investigador, porque si de burocracia hablamos, en esta causa usaron todo lo que pudieron, el mismo manifiesta que "consultada sobre cómo tiene conocimiento del tratamiento psiquiátrico que realiza la denunciada y los datos de la profesional respondió que Ana se lo contó anteriormente" (lo cual Ana desmintió). La invención del delincuente psiquiátrico es parte fundamental en este entramado de estigmatización carente de argumento, del cual forma parte el sistema judicial en su conjunto, donde en lugar de utilizar los recursos para obtener una visión amplia de los hechos, los operadores judiciales acusan, y basan sus acusaciones en dichos sin fundamentos. Eligen acusar y proponer un juicio abreviado, un acuerdo con la defensoría, en lugar de investigar y llegar a la verdad, proponiendo una solución de calidad del conflicto denunciado. Este desgano en investigar es consecuencia de la presión que existe en los tribunales para que se cierren casos, sin importar ni el motivo ni las personas involucradas.

Cuando afirmo que la justicia discrimina y estigmatiza, lo digo en el sentido amplio de la palabra, y para todos los estamentos. Ana, ante esta denuncia, solicitó un 
defensor oficial porque ya había gastado muchísimo dinero en abogados y le parecía una denuncia absolutamente ridícula y basada en mentiras:

cuando me informaron de que me acusaban no lo podía creer, realmente no puedo entender como una persona puede sentir tanto odio, que inventa hechos para perjudicarme. Esta mina metió toda la mierda que se le ocurrió en una batidora, para que algo de todo eso me salpique. Lo peor, es que en la justicia nadie te escucha, nadie te cree, nadie te defiende, ni tu defensor, imagínate.

En relación a esto último, Ana en una de las entrevistas relató como fue maltrata por su defensor oficial antes de la audiencia, quien le dijo tener muchos casos y que ella estaba muy ansiosa, y que él no era su psicólogo. A la vez que no la dejó declarar y cuya secretaria insistía con las pruebas que había aportado la exvecina. La construcción de Ana la loca acosadora, había tenido éxito, pese a no haber pruebas. Por haber un supuesto antecedente psiquiátrico, Ana es culpable. De los cuatro puntos que conforman la denuncia (hostigamiento por redes, hackeo de cuenta de Gmail, duplicación de cuenta de Facebook, intento de robo en su nuevo domicilio), dos fueron desestimados. El de robo, debido a que se entrevistó a la persona que la denunciante (exvecina) aportó como testigo, y la desmintió, manifestando que nunca había visto a Ana por el barrio. La del hackeo de la cuenta de Gmail, por tratarse de del ámbito privado, y porque de la investigación se desprende "preguntada si la empresa "Google" le dio aviso de que personas extrañas accedieron a su cuenta respondió que le llegaron mensajes de texto con números, que no sabe que significan”. Pero lo llamativo es que pese a quedar en evidencia el relato falaz de la denunciante en cuanto a los puntos anteriores, las otras denuncias, hostigamiento digital y duplicación de perfil de Facebook continúan en curso. En la declaración testimonial se observa:

Durante el mes de octubre de 2020 me duplico mi Facebook. Un día me escribió una amiga diciéndome “¿para qué te armaste otro face?” Y al corroborarlo vi que se había puesto mi nombre, mi foto, mis mismos cargos, todo igual. Sé que fue ella porque en la fecha de cumpleaños puso el suyo. Con esa cuenta amenazó a seguidores míos. Hice la denuncia vía correo electrónico. Consultada si el Facebook continúa abierto respondió que no, pero que resguardó las capturas de pantalla. 
Del expediente no se desprende ninguna investigación respecto a este punto, se sostiene la acusación solo en base a dichos, sin respaldo empírico alguno. En relación con el hostigamiento digital, tal como quedó demostrado respecto a los carteles que Ana colocó en su edificio, todos sus posteos y sus videos, fueron reclamando justicia por lo que ella esta padeciendo, en donde una vez más, la justicia hace oídos sordos y criminaliza a la víctima, porque algo habrá hecho, es mujer y loca.

La construcción de la loca peligrosa, la dicotomía de la mala contra la buena ciudadana, también está presente de parte de quien fuera denunciada por malversación de fondos y por difamación. En sus redes, se refería a Ana como "está loca, loca mal”, "es una persona que no está bien, antes me amaba pero como no le di bola se puso así, igual estaba mal de antes”, "a esta altura pareciera que se tratara de un comportamiento sistemático lo que me hace incluso dudar de su estado psíquico y de su salud mental", "esta loca, secuestro a un gato". Y desde cuentas falsas, comenzaron a comentar publicaciones de Ana con las siguientes agresiones "esquizofrénica mugrosa, estas para el psiquiátrico", "zafo de la esquizofrénica de esta desquiciada. Estas para el borda flaca”, entre otras cosas.

En el expediente, se define: "soy profesora de inglés, pero siempre estuve vinculada con proyectos y trabajos sociales con colectivos vulnerables. Esto comenzó, desde las escuelas donde trabajaba en Villa Fiorito e Ingeniero Budge, Pcia de Buenos Aires, y luego se trasladó a un proyecto humanitario en Delhi, India cuyo propósito es ayudar activamente a niños y niñas en estado de extrema pobreza y necesidad"

Por otra parte, la exvecina, manifiesta ser una futura abogada, perito de la Nación, asesora educativa. Es interesante el énfasis que pone en su supuesto rol en el Estado: "consultada sobre cómo tiene conocimiento de las medidas cautelares dispuestas respondió porque es perito del Poder Judicial de la Nación e ingresó al sistema para leer el expediente." En uno de los tantos mails que envió a la fiscalía para incriminar a Ana, adjunta un print de pantalla de una publicación en la que Ana cuenta un poco lo que le está sucediendo, y al pie de la imagen, la exvecina escribe "sigue mintiendo no hay penal la cautelar la gano porque mintió y no dejo defenderme, lo que porque soy perito y la fui siguiendo en silencio. Aberrante. Y jamás fui notificada”. ¿No es esto amenazante? Que una persona diga que es perito de la Nación, que va siguiendo de forma silenciosa la denuncia de su víctima y aun sabiendo que hay una medida cautelar en su contra, hace caso omiso, ¿no es una burla a la justicia, y un intento de demostrar poder? Preguntas que quedarán para una futura investigación. 


\section{A modo de conclusión}

Lejos de llegar a alguna conclusión respecto a la violación sistemática de los derechos humanos por parte del sistema judicial, en particular el aparato que interviene en el proceso penal contravencional de la Ciudad de Buenos Aires, son más las preguntas y dudas que esbozamos para futuros trabajos dentro del campo de la antropología jurídica. Puedo afirmar, tal como desarrollé a lo largo de este trabajo, que el MPF no solo ejerce violencia institucional y de género, sino que la reproduce y es herramienta necesaria para esta última. Lo escuchamos y lo leemos en todos los casos de femicidios: a las mujeres no nos creen, nos consideran exageradas (más aún cuando no tenés "marcas"), nos tratan de locas. No hay, por parte de las instituciones, un trabajo interdisciplinario eficiente, debido a que su motivación no es la eficiencia en la calidad de la resolución, sino en el caso cerrado, en las estadísticas. La mejor fiscalía o juzgado es aquella que cerró más casos, no aquella donde se murieron menos mujeres, o se lograron respetar mayor cantidad de perimetrales, o donde se arrestaron o juzgaron a los hostigadores.

La etnografía, como metodología de nuestra disciplina, nos posibilita la llegada a la densidad de la cultura, a esos intersticios que parecen imperceptibles, inaccesibles. Es desde ellos, desde aquellos lugares comunes del proceso judicial (la pregunta, la omisión, "el consejo"), que podemos advertir la reproducción de prácticas que garantizan y legitiman la violencia institucional jurídica.

Si los esfuerzos y los recursos puestos al servicio de la construcción de la loca mala, fueran puestos al servicio de la búsqueda real de justicia, con todo lo que eso implica, no tendríamos 1 femicidio cada 37 horas en nuestro país. La incriminación por sospecha, la omisión, la suspensión de juicio a prueba, son herramientas de las que se vale el sistema jurídico, para mejorar sus estadísticas, para cerrar filas en su pacto corporativista letrado. El Observatorio Ahora que si nos ven, menciona discriminadamente, cuantos femicidas correspondían a las fuerzas de seguridad. Es necesario también, obtener información respecto a cuantos están vinculados al sistema judicial, dado que creo nos llevaríamos una ingrata sorpresa, aunque evidente, por lo menos para mí.

El sistema judicial, sigue siendo misógino, no solo por la cantidad de hombres que forman parte de esto, sino por las mujeres que practican una misoginia internalizada que es tan o más perversa que la de sus pares. 


\section{Referencias}

Eilbaum, Lucía, (2004) "La sospecha como fundamento de los procedimientos policiales", en "Cuadernos de Antropología Social", Sección Antropología Social-ICA, no 20, Facultad de Filosofía y Letras, UBA, Buenos Aires.

Geertz, Clifford, (1987) La interpretación de las culturas, Gedisa, México.

Malinowski, Bronislaw, (1973) Crimen y costumbre en la sociedad salvaje, Ariel, Buenos Aires.

Martínez, María Josefina; Pita, María Victoria y Palmieri, Gustavo, (1998) “Detenciones por averiguación de identidad: policía y prácticas rutinizadas", en Inés Izaguirre (comp.), Violencia social y derechos humanos, Eudeba, Buenos Aires.

Mauss, Marcel, (1979) "Ensayo sobre los dones. Motivo y forma del cambio en las sociedades primitivas", en Sociología y Antropología, Tecnos, Madrid.

Pita, María Victoria (2016) "Pensar la violencia institucional: vox populi y categoría política local”, en Espacios de Crítica y Producción, núm. 53, pp. 33-42.

Tiscornia, Sofía, (1998a) "Violencia policial. De las prácticas rutinarias a los hechos extraordinarios", en Izaguirre, I. (comp.), Violencia social y derechos humanos, Eudeba, Buenos Aires.

- (1998b) "Violencia y cultura en la Argentina”, en Neufeld, Grimberg, Tiscornia y Wallace (comps.), Antropología Social y Politica. Hegemonía y poder: el

mundo en movimiento, Eudeba, Buenos Aires.

- (2008) Activismo de los derechos humanos y burocracias estatales. El caso Walter Bulacio, CELS, Buenos Aires. 